\title{
Soil water characteristic curve parameters of collapsible sand in Lambayeque, Peru
}

\author{
Miguel Isidro $^{1 *}$ Pablo Trejo ${ }^{1}$, and Marko López ${ }^{2}$ \\ ${ }^{1}$ Postgraduate Department of Civil Engineering, National University of Engineering, Ave. Tupac Amaru 210, Rimac, Lima, Peru. \\ ${ }^{2}$ Department of Civil Engineering, University of Lima, Ave. Javier Prado 4600, Santiago de Surco, Lima, Peru.
}

\begin{abstract}
Several structures are built on collapsible soils in the mining and petroleum industries and on civil sites. In order to analyze the stability of such structures, one must properly study the unsaturated soil behavior. Collapsible soils are frequent sand soil that are susceptible to a significant and sudden reduction in volume upon wetting. An important factor is matric suction, which es related to moisture content through the soil water Characteristic Curve (SWCC), the SWCC is obtained through a filter paper technique and provides a valuable relationship between suction and water content unique to soils. This measures the influence of parameters on the behavior of the structure of collapsible soil. Interactions between structure and soil must be properly evaluated as the bearing capacities of shallow and deep foundations are linked to properties of soil suction, moisture, and grade saturation. This work has experimentally measured the parameters of suction and moisture on the behavior of collapsible sands, where an oil storage tank will be built in the city of Lambayeque in Peru. Undisturbed soil specimens obtained from geotechnical exploration campaigns were used. The filter paper method used in this study was that proposed by models of BrooksCorey and Van Genuchten. Results show consistent values near reported values from literature.
\end{abstract}

\section{Introduction}

The cost of performing measurements of unsaturated soil properties in laboratory is high. For this reason, in Peru, most soil laboratories do not have the required equipment to measure the properties of unsaturated soils. However, the knowledge of such properties, as the suction, the moisture content and the relative permeability are fundamental for a proper representation of unsaturated soils. Indeed, measurements of unsaturated soil properties have encouraged the pursuit of more comprehensive constitutive models for numerical applications in geotechnical engineering. Unsaturated soil properties are usually represented through soil water characteristic curves (SWCCs) that relates moisture content with soil suction. As a first estimate, the SWCC can be obtained from a grain-size distribution curve, reducing further costs $[1,2]$. Nevertheless, experimental programs in laboratory remain as the best choice for the assessment of SWCCs.

SWCC primarily depends on factors such as soil types, grain-size distribution, soil plasticity, and the initial void ratio [3]. The saturated water content and air-entry value (or bubbling pressure), $\left(u_{a}-u_{w}\right)_{b}$, generally increase with the plasticity of the soil. Other factors such as stress history and secondary soil structure also affect the shape of the SWCCs [2]. SWCC fitting models generally consider volumetric water content as the main variable; however, they can also be expressed with respect to the degree of saturation and gravimetric water content [4].
The experimental techniques commonly used for measuring or controlling soil suctions vary widely in terms of cost, complexity, and measurement range. There are several methods to predict the SWCC and are broadly grouped into direct and indirect methods [5]. Direct methods include Buchner funnels, tensiometers, pressure membranes and pressure plates [6-9]. These methods measure the pore-water pressure in the soil or impose a known air pressure to the soil and allow the moisture content to equilibrate with the imposed air pressure. Direct methods are recognized for higher accuracy. However, they are expensive and time-consuming.

On the other hand, indirect methods are attractive for their fast and simple usage as well as their low cost [10]. These are the main reasons for their increased use, mainly in spatial variability studies [1]. Indirect methods include filter papers and heat dissipation sensors [11]. These methods use measurements or indicators of water content or another physical property sensitive to water content variation.

Once laboratory data are available, constitutive relationships based on experimental or empirical equations can be used to help define the SWCC. A wide range of models have been developed to define the retention curve, which are characterized by the adjustable parameters that provide great flexibility for the representation of different types of soil. The mathematical equations used in these models involve empirical adjustment parameters that are related to the different characteristic points and regions of the curve [1].

\footnotetext{
${ }^{*}$ Corresponding author: misidroc@uni.pe
} 
Besides soil characteristic curves, it is important the measurement of additional properties to identify if unsaturated soils are prone to trigger collapse deformation. Such behavior is typical of unsaturated low dry density soils and has been reported in several places of the world. In laboratory, the classical oedometer test with some adaptations has been used to characterize and quantify soil collapse. In conventional oedometer tests, the unsaturated soil sample is loaded until a load of interest and after reaching forces equilibrium, the soil is wetted while induced further deformations are measured. In more sophisticated oedometer tests, the suction is controlled, allowing a detailed description of the collapse phenomenon [12-14]. Field tests also have been performed with procedures similar to those adopted in laboratory. Such tests consider plate and pile load, cone penetration, and special load tests [15].

The objective of this study is to characterize experimentally a sandy soil in a location where an oil storage tank will be built in the city of Lambayeque in Peru. Undisturbed soil specimens were obtained from geotechnical exploration campaigns. In order to address soil collapse hazards, standard oedometer tests were used for the assessment of a soil collapse index. The filter paper method was used in order to assess points of the characteristic curves of the sandy soil. From those points, we obtain the required parameters for the adoption of the empirical Brooks-Corey and Van Genuchten models.

\section{Testing Materials}

The soil specimens used in this study were taken from The Eten terminal, approximately $20 \mathrm{~km}$ south of the city of Chiclayo in Peru. Fig. 2 shows the color and texture of the soil particles, indicating a sandy soil. Sands with a color of cream, pale cream to gold, or caramel are relatively consolidated.

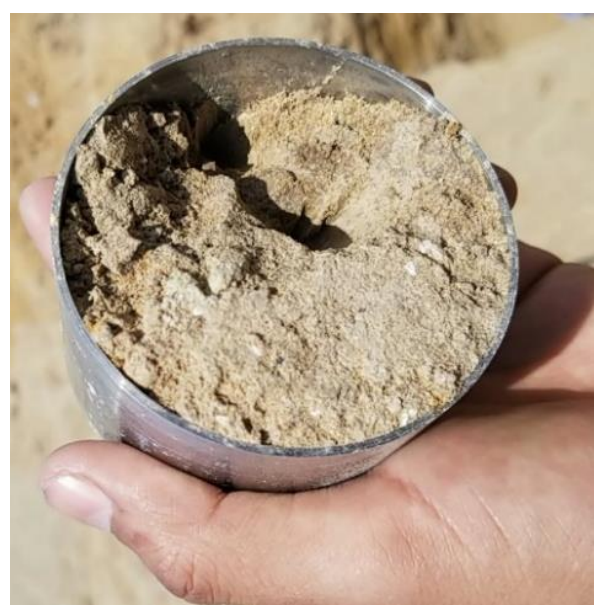

Fig. 2. Visual-manual classification of collapsible sand.

Several samples were collected to investigate the physical properties of the sand, including moisture content, particle size distribution, the Atterberg limit, and specific gravity. The Unified Soils Classification System (USCS) was used for soil classification. The basic physical properties of the sand are presented in Table $\mathbf{1 .}$
Table 1. Physical properties of the sandy soil.

\begin{tabular}{ccc}
\hline Properties & Unit & Sample \\
\hline Particle size distribution & Gravel (\%) & 0.0 \\
& Sand (\%) & 96.8 \\
& Fines (\%) & 3.2 \\
& $\mathrm{D}_{10}(\mathrm{~mm})$ & 0.09 \\
& $\mathrm{D}_{30}(\mathrm{~mm})$ & 0.14 \\
& $\mathrm{D}_{60}(\mathrm{~mm})$ & 0.19 \\
& $\mathrm{C}_{\mathrm{u}}$ & 2.01 \\
& $\mathrm{C}_{\mathrm{c}}$ & 1.02 \\
Plastic limit & $\mathrm{PL}$ & 20 \\
Liquid limit & $\mathrm{LL}$ & 29 \\
Plasticity index & $\mathrm{PI}$ & 9 \\
Specific gravity & $\mathrm{G}_{\mathrm{s}}$ & 2.44 \\
USCS & & SP \\
\hline
\end{tabular}

Fig. 3 shows the particle size distribution (gradation) of sand obtained through a sieve analysis and a sedimentation process using a hydrometer.



Fig. 3. Particle size analysis (sieve and hydrometer analysis combined).

According to the USCS, the collapsible sand is classified as poorly graded with little fines (SP). The distribution of particle sizes smaller than $75 \mu \mathrm{m}$ and present silt at $79.5 \%$ and clays at $20.5 \%$.

For a better understanding of the soil in terms of elemental content of total soluble salts, chlorides, sulfates, and acidity $(\mathrm{pH})$, chemical tests were carried out. Results are shown in Table 2. It can be observed that the contents of soluble salts and chlorides are aggressive (damaging) for a concrete structure and/or reinforced concrete. Depending on the amount of sulfate, the standards recommend the use of a Portland cement, Type I. However, since the concrete will be exposed to marine aggression, Type $\mathrm{V}$ cement is recommended for all concrete and reinforced concrete structures.

Table 2. Soil chemical analysis.

\begin{tabular}{c|c|c|c}
\hline $\begin{array}{c}\text { Total } \\
\text { soluble salts } \\
(\mathrm{ppm})\end{array}$ & $\begin{array}{c}\text { Soluble } \\
\text { chlorides } \\
(\mathrm{ppm})\end{array}$ & $\begin{array}{c}\text { Soluble } \\
\text { sulfates }(\mathrm{ppm})\end{array}$ & $\mathrm{pH}$ \\
\hline 21734.00 & 860.92 & 209.34 & 8.56 \\
\hline
\end{tabular}




\section{Methodology}

\subsection{Collapse testing}

In order to characterize and to quantify the soil collapse, oedometer tests, in accordance with [16], were performed over soil samples of $19.40 \mathrm{~mm}$ height and 5.95 $\mathrm{mm}$ diameter. Such tests are performed in two steps. In the first step, four unsaturated soil specimens are loaded at $0.01,0.8,1.6$ and $3.2 \mathrm{~kg} / \mathrm{cm}^{2}$. In the second step, the specimens are wetted and the additional vertical deformation is measured. In this sense, further positive deformations indicate a volumetric expansion of the soil while negative deformations indicate the soil collapse. Fig. 4 shows the obtained results. It can be noticed that for the first specimen, loaded at $0.01 \mathrm{~kg} / \mathrm{cm}^{2}$, the soil presents a volumetric expansion when is wetted. On the other hand, the other soil specimens, subjected to larger loads, present collapse deformations. In accordance with [15], a strain of 2.53 was determined for a stress of 1.6 $\mathrm{kg} / \mathrm{cm}^{2}$ and 5.04 for a stress of $3.2 \mathrm{~kg} / \mathrm{cm}^{2}$. In this investigation, the average weight of an oil storage tank was estimated, which translates into a range of $1.6 \mathrm{~kg} / \mathrm{cm}^{2}$ to $3.2 \mathrm{~kg} / \mathrm{cm}^{2}$ that will be loaded to the ground.

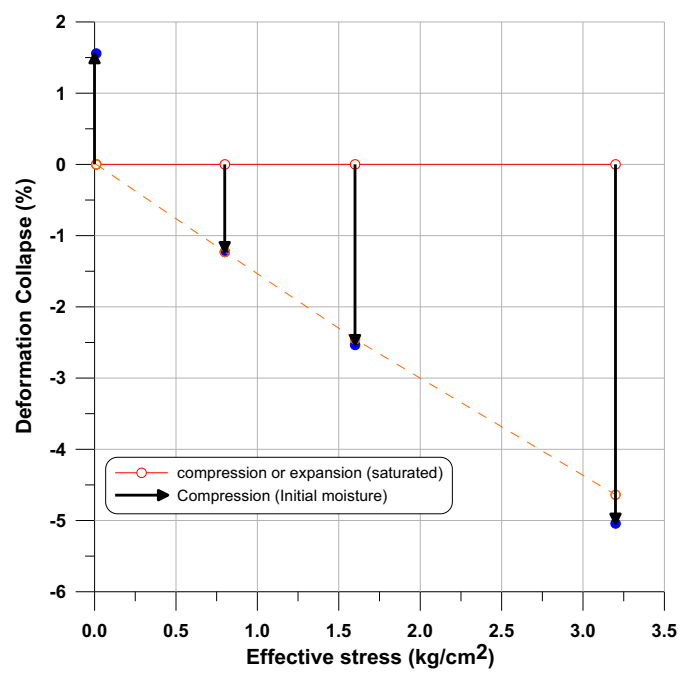

Fig. 4. Oedometer test results used to characterize the collapse of soils from the Eten terminal in Lambayeque, Peru.

In accordance with $[12,13]$, Table 3 presents the collapse index $\left(i_{c}\right)$ intervals, where it is observed that the value of the index is dependent of the vertical stress applied to the soil.

Table 3. Classification of collapse index ( $\left.\mathrm{i}_{\mathrm{c}}\right)$.

\begin{tabular}{c|c}
\hline Degree of collapse & $\mathrm{i}_{\mathrm{c}}(\%)$ \\
\hline None & 0 \\
Slight & 0.1 to 2.0 \\
Moderate & 2.1 to 6.0 \\
Moderately severe & 6.1 to 10.0 \\
Severe & $>10$ \\
\hline
\end{tabular}

Relating the deformations found from Fig. 4, the maximum deformation of 5.04 was established as the collapse index of the soil, which corresponds to a moderate degree in terms of the collapse index.

\subsection{Filter paper method}

There are several indirect methods available to measure matrix suction. For this work, we used the filter paper test in accordance with Bicalho [17]. This test uses the pressure of the water inside the test body so that a filter paper can flow before finding the hydraulic balance. The calibration curve for Whatman grade 42 was proposed by different authors throughout the years in accordance with Bicalho. The calibration used according to ASTM was the following:

$$
\begin{aligned}
& \mathrm{wc}_{\mathrm{fp}}>45.3 \%: \log _{10} S=5.327-0.0779\left(\mathrm{wc}_{\mathrm{fp}}\right) \\
& \mathrm{wc}_{\mathrm{fp}}>45.3 \%: \log _{10} S=2.412-0.0135\left(\mathrm{wc}_{\mathrm{fp}}\right)
\end{aligned}
$$

where $S$ is suction and $\mathrm{wc}_{\mathrm{fp}}$ is the gravimetric water content of the filter paper in percentage.

The matrix suction measurement was indirectly achieved using filter paper in accordance with [18]. For the test preparation, we focused on obtaining undisturbed samples with a 3" diameter beveled ring for a depth of one meter from the selected site. The samples were completely filled in the entire volume of the ring. Subsequently, the rings were wrapped with fill paper, insulating tape, aluminum foil, and a split bag (4 micron). These were placed in an expanded polystyrene box for transport to the laboratory. The samples were dried to carry out the wetting process. A spray bottle was used to supply water in a controlled manner to the specimen, and the ratio of increase in humidity was obtained by spraying towards the ring containing the sand. Each specimen was prepared at certain humidity. In this case the samples were prepared at $9.15 \%, 12.11 \%, 13.57 \%, 14.56 \%, 16.13 \%, 18.57 \%$ and $21.12 \%$ to provide a range of suctions for the measurements. The test was carried out until the expected humidity was reached, and Whatman grade 42 paper filters were used. Each paper filter was placed in a desiccator 24 hours before starting the test. Three Whatman papers were then placed: two with a larger diameter and one in the middle with a smaller diameter. It is necessary to control the weight of each specimen and beveled ring before placing the paper. After 14 days, the Whatman paper located in the center was removed for analysis. The weight of the water accumulated by matrix suction was recorded using a balance with a precision of $0.0001 \mathrm{~g}$; subsequently, the specimen was placed in a desiccator. Finally, it was reweighed to obtain the amount of moisture gained by the filter paper. Fig. 5 shows all the steps performed along the experimental test using the filter paper method.

\section{Estimation of SWCC}

\subsection{Brooks and Corey}

Reference [19] used a large amount of experimental data, and by comparing these values with each other, they concluded that the retention curve of a soil can be expressed by the equation: 


$$
\theta_{n v}=\frac{\theta-\theta_{r}}{\theta_{s}-\theta_{r}}=\left(\frac{\psi_{a}}{\psi}\right)^{\lambda} \text { with } \varphi>\varphi_{a}
$$

where $\Theta_{n v}$ is the normalized volumetric water content, $\psi_{a}$ is the air inlet value, and $\lambda$ is a characteristic soil parameter known as the pore size distribution index, and is related to the slope of the curve [20].

\subsection{Van Genuchten}

The model proposed by [21] relates the normalized volumetric water content with the soil suction through the equation:

$$
\theta_{n v}=\frac{\theta-\theta_{r}}{\theta_{s}-\theta_{r}}=\left[\frac{1}{1+(\alpha \varphi)^{n}}\right]^{m}
$$

where $\alpha$ is a parameter that represents the entry point of air from the ground and is related to the inverse of this value, $n$ is a parameter that controls the slope of the curve at the air intake point, and $m$ is a parameter that rotates the sloping portion of the curve and the lower plateau about a point above the crest of the curve [21].
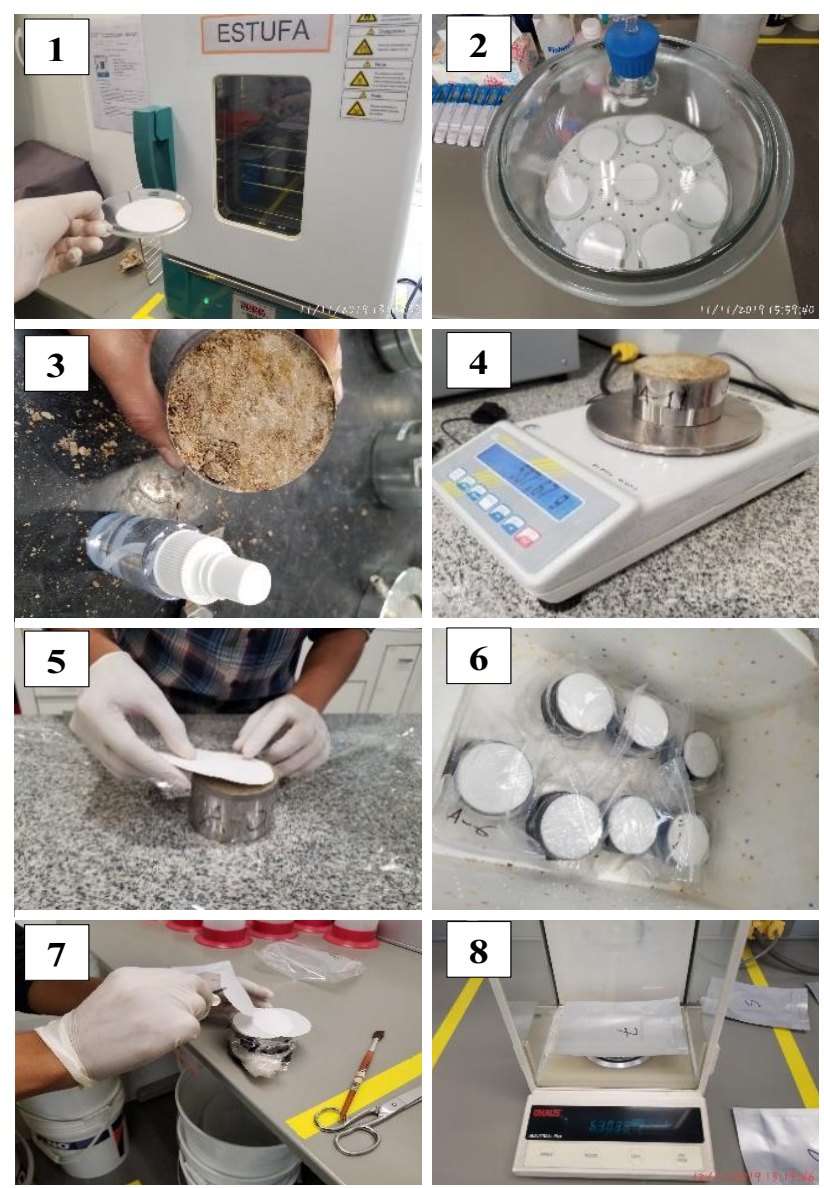

Fig. 5. Sample preparation steps using the filter paper method.

\section{Results}

The soil water characteristic curve was measured for collapsible sands. Table 4 shows a summary of the experimental data of the studied soil.

The experimental data are in the ranges obtained for sandy soils that reach a limit of approximately $150 \mathrm{kPa}$ of matrix suction $[22,23]$.

Table 4. Experimental results.

\begin{tabular}{c|c}
\hline$\Psi(\mathrm{kPa})$ & $\theta_{\mathrm{v}}(\%)$ \\
\hline 14.56 & 35.20 \\
15.74 & 30.95 \\
20.27 & 26.88 \\
31.17 & 24.27 \\
58.90 & 22.63 \\
79.32 & 20.19 \\
135.86 & 15.26 \\
\hline
\end{tabular}

The experimental points were used to obtain the adjustment parameters for model creation of [19] and [21] using the SWRC FIT program. These parameters are listed in Table 5.

Table 5. SWCC parameters obtained from experimental

\begin{tabular}{c|c|c}
\multicolumn{3}{|c}{ data. } \\
\hline SWCC & $\begin{array}{c}\text { Van } \\
\text { Genuchten }\end{array}$ & $\begin{array}{c}\text { Brook and } \\
\text { Corey }\end{array}$ \\
\hline$\theta_{s}$ & 0.38505 & 0.3766 \\
$\theta_{r}$ & 0.084319 & 0.11958 \\
$\alpha$ & 0.068661 & - \\
$\lambda$ & - & 0.64096 \\
$\Psi_{a}$ & - & 10.645 \\
$n$ & 1.5791 & - \\
$m$ & 0.3667 & - \\
\hline
\end{tabular}

The program "SWRC Fit" was used for a nonlinear fitting of soil water retention curves. Furthermore, such program allows the evaluation of five models by the Levenberg-Marquardt method. The SWRC Fit automatically determines the required conditions for nonlinear fitting, such as the initial estimate of the parameters; and therefore, users can simply input the soil water retention data to obtain the necessary parameters. The program can be executed directly from the web at http://purl.org/net/swrc/ [24].

Fig. 6 shows the results of the characteristic curves of the collapsible sands obtained by the filter paper test. Also, experimental data was compared with the curves obtained by models in [19] and [21] which show good fits. The results of the experimental suction values are below the $140 \mathrm{kPa}$ limit value for all types of sand. 


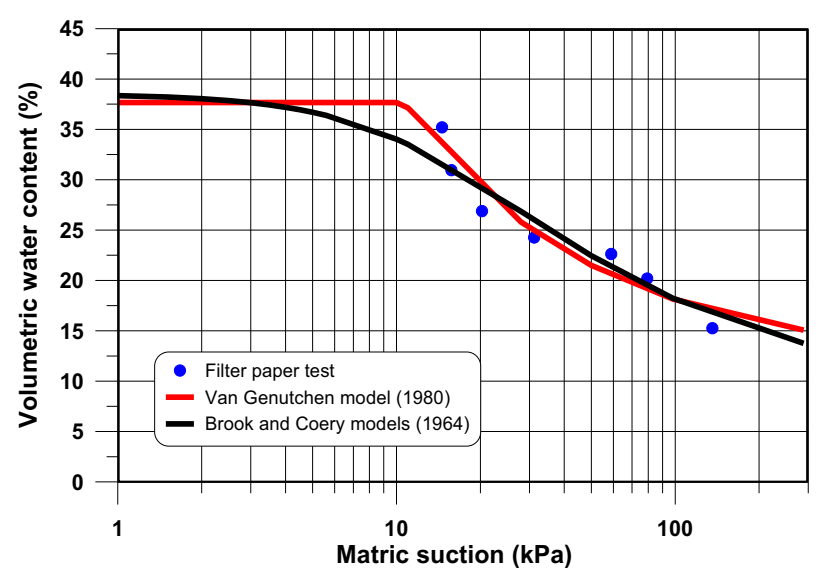

Fig. 6. Characteristic curve of the sands at Eten's Port obtained by the filter paper test.

There are different factors (soil density, grain-size distribution, etc.) in a sandy soil that have a significant effect on SWRC. A small variation in density or grainsize shifts the SWRC curve on the vertical axis (volumetric water content).

Fig. 7 presents a comparison of the characteristic curve with other authors [22, 23]. It is observed that [23] presents a behavior closer to experimental data, due to a similar distribution of the grain size.

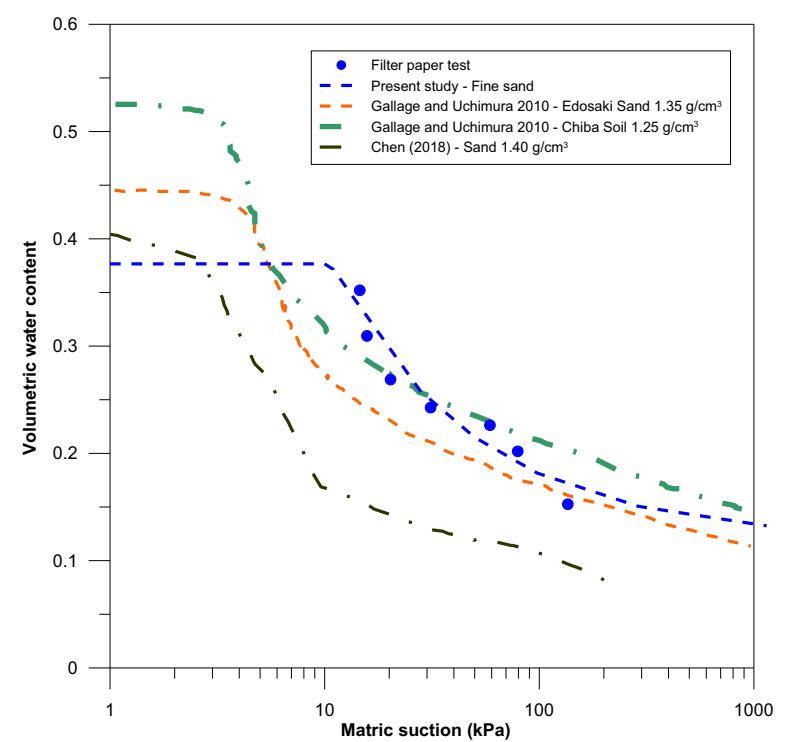

Fig. 7. Characteristic curve comparisons of the sands of Eten with other authors.

\section{Conclusions}

In this study, we performed an experimental characterization of a sandy soil located in northern Peru. The laboratory tests include the measurement of collapse deformation owing to soil wetting. From the obtained results, it was realized that the soil is prone to trigger collapse deformation in a moderate degree.

For the assessment of the characteristic curves, we used the technique using Whatman grade 42 contact filter paper. Such technique proved to be a faster and simpler method to determine the soil water retention curve. The SWCC of the collapsible sand was produced using the filter paper test, and it was compared to the mathematical models proposed by Brooks and Corey and Van Genuchten. Both models produced almost identical results to the laboratory data. It could be used to predict permeability coefficients and SWCC for the collapsible sand. The obtained results are within the experimental range of values obtained by other authors [22, 23]. Therefore, it is concluded that this methodology allows to obtain good results for collapsible soils due to the fact that its structure in its natural state presents stability.

Currently, with the implementation of this methodology, other factors that intervene in the SWRC curve for collapsible soil are being evaluated in the laboratory. In addition, a series of plate tests are being carried out to obtain a correlation between the matrix suction and bearing capacity of the soil for better analysis of the soil-structure interaction in gas storage tanks in Lambayeque. Further studies are been considered in order to use the obtained unsaturated soil properties through numerical modelling in a more comprehensive way.

\section{Acknowledgments}

The authors would like to acknowledge the geotechnical laboratory of the University of Lima, Peru and the PTN Consultores Company for the financial support and interest in this study.

\section{References}

1. M. Azmi, M.H. Ramli, M.A. Hezmi, S.A.N. Mohd Yusoff, , M.N.A. Alel. (2019). Estimation of Soil Water Characteristic Curves (SWCC) of mining sand using soil suction modelling. IOP Conf. Ser.: Mater. Sci. Eng. 527, doi: 10.1088/1757-899X/527/ 0012016

2. D.G. Fredlund, H. Rahardjo, M.D. Fredlund. (2012). Unsaturated soil mechanics in engineering practice (John Wiley \& Sons, Hoboken)

3. W. Hong, Y. Jung, S. Kang, J. Lee. (2016). Estimation of Soil-Water Characteristic Curve in Multiple-Cycles using membrane and TDR system. Materials 9:1019. doi: 10.3390/ma9121019

4. H.A. Nandar. (2018). Application of unsaturated soil mechanics to foundation engineering (National Autonomous University of Mexico, Master's thesis, Ciudad de Mexico)

5. A. Johari, G. Habibagahi, A. Ghahramani. (2006) Prediction of soil-water characteristic curve using genetic programming. Journal of Geotechnical and Geoenvironmental Engineering. 132:5,661-665, doi: 10.1061/(ASCE)1090-0241(2006)132:5(661)

6. O.M. Oliveira \& F.A.M. Fernando. (2006). Study of equilibration time in the Pressure Plate. 4th Int. Conf. on Unsaturated Soils, 1864-1874, doi: 10.1061/40802(189)157

7. R. Sharma \& M. Mohamed. (2006). Evolution of degree of saturation and suction relationships under dynamic flow. 4th Int. Conf. on Unsaturated Soils, 1494-1502, doi: 10.1061/40802(189)124 
8. S. Lourenço, D. Gallipoli, D. Toll, F. Evans, G. Medero. (2007). Determination of the soil water retention curve with tensiometers. Experimental Unsaturated Soil Mechanics. 112,95-102. doi: 10.1007/3-540-69873-6_9

9. S. Sreedeep \& D.N. Singh. (2005). Methodology for determination of osmotic suction of soils. Geotechnical and Geological Engineering. 24:1469-1479, doi: 10.1007/s10706-005-1882-7

10. T. Abeykoon, R. Udumkumburage, C. Gallage, T. Uchimura. (2017). Comparison of direct and indirect measured soil-water characteristic curves for silty sand. International Journal of GEOMATE. 13:39, 916, doi: 10.21660/2017.39.170519

11. A. Reder, G. Rianna, L. Pagano. (2014). Calibration of TDRs and heat dissipation probes in pyroclastic soils. Procedia Earth and Planetary Science 9:171179. doi: 10.1016/j.proeps.2014.06.016.

12. S. Houston, W. Houston, C. Zapata, C. Lawrence. (2001). Geotechnical engineering practice for collapsible soils. Geotechnical and Geological Engineering 19:333-355, doi: 10.1023/A:10131782 26615.

13. ASTM D5333-03. Standard Test Method for Measurement of Collapse Potential of Soils (Withdrawn 2012), ASTM International, West Conshohocken, PA, 2003. doi: 10.1520/D5333-03

14. E. Leong, L. He, H. Rahardjo. (2002). Factors affecting the filter paper method for total and matric suction measurements. Geotech. Test. J. 25:3, 321332, doi: 10.1520/GTJ11094J

15. O.M. Vilar \& R.A. Rodrigues. (2015). Revisiting classical methods to identify collapsible soils. Soil and Rocks. Brazilian Soc Soil Mechanics \& Geotechnical Engineering. 38:3, 265-278, doi: hdl.handle.net/11449/158814.

16. ASTM D4546-14e1, Standard Test Methods for One-Dimensional Swell or Collapse of Soils, ASTM International, West Conshohocken, PA, 2014. doi: 10.1520/D4546-14E01

17. K. Bicalho, F Marinho, J. Fleureau, A. Gomes, S. Ferreira. (2009). Evaluation of filter paper calibrations for indirect determination of soil suctions of an unsaturated compacted silty sand. 17th International Conference on Soil Mechanics and Geotechnical Engineering. 1, 777-780. doi: 10.3233/978-1-60750-031-5-777.

18. ASTM D5298-16, Standard Test Method for Measurement of Soil Potential (Suction) Using Filter Paper, ASTM International, West Conshohocken, PA, 2016. doi: 10.1520/D5298-16.

19. R. Brooks \& A. Corey. (1964). Hydraulic properties of porous media. Hydrology paper. 3,27.

20. E.C. Leong \& H. Rahardjo. (1997). Review of SoilWater Characteristic Curve Equations. Journal of Geotechnical and Geoenvironmental Engineering. 123:12, 1106-1117, doi: 10.1061/(ASCE) 10900241(1997)123:12(1106)
21. M.T. Van Genuchten. (1980). A Closed-form Equation for Predicting the Hydraulic Conductivity of Unsaturated Soils. Soil Sci Soc Am J. 44:892-898, doi: 10.2136/sssaj1980.03615995004400050002x.

22. Y. Chen. (2020). Soil-Water retention curves derived as a function of soil dry density. Geohazards. 1:1,3-19. doi: 10.3390/geohazards 101 0002

23. C.P.K. Gallage \& T. Uchimura. (2010). Effects of dry density and grain size distribution on soil-water characteristic curves of Sandy soils. Soils and Foundations. 50:1,161-172, doi: 10.3208/sandf.50.1 61

24. K. Seki. (2007). SWRC fi t-A nonlinear fitting program with a water retention curve for soils having unimodal and bimodal pore structure. Hydrol. Earth Syst. Sci. Discuss. 4,407-437, doi: 10.5194/hessd-4-407-2007 